\title{
Variations and indication of stable isotopes in different zones of sandstone-hosted uranium deposits
}

\author{
HAO SONG ${ }^{* 1}$, GUOXIANG CHI ${ }^{2}$, SHIJUN NI ${ }^{1}$, \\ CHENGJIANG ZHANG ${ }^{1}$
}

${ }^{1}$ Chengdu University of Technology, Chengdu, Sichuan 610059, China

${ }^{2}$ Department of Geology, University of Regina, Regina, Saskatchewan S4S 0A2, Canada

*E-mail:songhhao@163.com

A comprehensive sorting reviewing data is needed to sort and uncover the relationship between variations and indication of stable isotopes in different zones of sandstonehosted uranium deposits in northern China. The uranium mineralization in northern China is closely associated with clay alteration and carbonate cementation. Sandstone-type U mineralization is known from the coal-bearing Early-Middle Jurassic dark clastic sediments and from Paleogene variegated clastic sediments. We compiled all the data of hydrogen and oxygen isotopes of clay minerals and oxygen and carbon isotopes of carbonate from the sandstone-hosted uranium deposits in northern China, with an aim to characterize the spatial distribution of stable isotope signatures, especially with references to the zonation of clay alteration, and to evaluate their significance for the mineralization processes, especially the ore precipitation mechanisms in sandstonehosted uranium deposits. Song et al. $(2016,2019)$ note that deviation of $\mathrm{H}-\mathrm{O}-\mathrm{C}$ isotopes from the general variation trends as expected from the above redox mechanism likely resulted from the dynamic nature of the redox front. Hydrodynamic balance between a downward flow of uranium-bearing, oxidizing fluid and an upward flow of reductants-bearing, reducing fluid from the lower part of the basin is used to contribute a new conceptual mineralization model for the sandstone-hosted uranium deposits in the southern margin of the Yili Basin. The stable isotope systematics in the southern margin of the Yili Basin support a model in which a downflowing, uranium-carrying, oxidizing fluid of meteoric water origin, driven by gravity (topography), met with an upward flowing, reducing agent-carrying (including hydrocarbons) fluid from lower part of the basin, driven by fluid overpressures. Mixing of the two fluids resulted in uranium precipitation at the redox front (transitional zone).

References

Song H, Ni S, Chi G, Zhang C, Hou M, Liu H, Wang G, Yan W. 2019. Ore Geology Reviews, 107: 615-628.

Song, H., Ni, S.J., Hou, M.C., Zhang, C.J., Shi, Z.Q., Wang, G., Yang, B., Hu, Y., Chen, Y.J., 2016. Acta Geol. Sin. 90 (12), 33523366 (in Chinese with English abstract). 